\title{
Turning Vision into Reality: Successful Integration of Primary Healthcare in Taber, Canada
}

\author{
Transformer la vision en réalité : \\ intégration fructueuse des soins de \\ santé primaires à Taber, Canada
}

\begin{abstract}
by ROBERT WEDEL, MD
Rural Family Physician

Co-Leader, Taber Health Project

Associate Clinical Professor, Faculty of Medicine, University of Calgary Assistant Clinical Professor, Faculty of Medicine, University of Alberta Medical Director, Palliative Care, Chinook Health Region Taber, $A B$
\end{abstract}

\author{
RUTH GRANT KALISCHUK, RN, PHD \\ Associate Professor, SEARCH Canada Faculty \\ School of Health Sciences, University of Lethbridge \\ Lethbridge, $A B$
}

EILEEN PATTERSON, MCE

Coordination Consultant, Chronic Disease Management \& Prevention Network Lethbridge, $A B$ 


\title{
Turning Vision into Reality
}

SHARON BROWN, BSC

\author{
Research Assistant, SEARCH Canada \\ University of Lethbridge \\ Lethbridge, $A B$
}

\begin{abstract}
Primary healthcare offers significant benefits to Canadians and to the healthcare system as a whole. The Taber Integrated Primary Healthcare Project (TIPHP) was a three-year primary healthcare renewal initiative involving rural physicians and the Chinook Health Region in Taber, Alberta, Canada. The goal of the project was to improve healthcare services delivery through integration of the services provided by the physician group and the health region in one rural community. Four main enablers emerged as fundamental to the integration process: community assessment and shared planning; evidence-based, interdisciplinary care; an integrated electronic information system; and investment in processes and structures that support change.

The outcome of the project has been the implementation of a new model of healthcare delivery that embraces an integrated collaborative team approach in delivering population-based, primary healthcare. Importantly, the TIPHP has influenced regional healthcare policy related to primary healthcare renewal strategies and partnerships.
\end{abstract}

\section{Résumé}

Les soins de santé primaires offrent des avantages substantiels aux Canadiens et à l'ensemble du système de soins de santé. Le Taber Integrated Primary Healthcare Project (TIPHP) était une initiative triennale de renouvellement des soins de santé primaires à laquelle participaient des médecins travaillant en milieu rural et la Région sanitaire de Chinook à Taber, en Alberta, Canada. Le projet avait pour but d'améliorer la prestation des services de santé par l'intégration des services fournis par le groupe de médecins et la Région sanitaire dans une communauté rurale. Quatre grands facteurs se sont avérés fondamentaux au processus d'intégration : l'évaluation communautaire et la planification partagée; des soins interdisciplinaires fondés sur des preuves; un système d'information électronique intégré et des investissements dans les processus et les structures qui favorisent le changement.

Le projet sest soldé par la mise en ouvre d'un nouveau modèle de prestation de services de santé en vertu duquel une équipe de collaboration intégrée fournit des soins de santé primaires axés sur la population. Le TIPHP a surtout influencé les politiques de santé régionales ayant trait aux stratégies de renouvellement des soins de santé primaires et aux partenariats connexes. 


\section{Introduction}

In Canada, primary healthcare has received increasing attention in both political and organizational arenas. Primary healthcare has been described as both "a philosophy and an approach to providing health care resources. Its basic elements are essential health care, socially acceptable and affordable methods and technology, accessibility, public participation, and intersectoral collaboration" (Beddome et al. 1993: 13). Importantly, Starfield and Shi (2002) maintain that countries with weak primary healthcare infrastructures also demonstrate poorer performance on major health indicators. In terms of philosophy, primary healthcare is about "transforming the way the health care system works today - taking away the almost overwhelming focus on hospitals and medical treatments, breaking down the barriers that too frequently exist between health care providers, and putting the focus on consistent efforts to prevent illness and injury, and improve health" (Romanow 2002: 116).

Primary healthcare renewal can best be achieved by restructuring the healthcare system in identifiable ways, including utilizing population health research, integrating healthcare services delivery, creating sustainable collaborative partnerships and practices, improving cost-efficiency within the healthcare system and developing and implementing social and healthcare policy (Alberta Health and Wellness 2002; Romanow 2002). Numerous authors have emphasized the importance of integrating services delivery in primary healthcare reform (Mazankowski et al. 2001; Romanow 2002). These authors suggest that efficient and effective healthcare needs to be provided by qualified healthcare professionals who deliver related services within proximity in a coordinated and timely manner.

Although healthcare professionals are aware of needed improvements and have access to existing models, in practice, integrated primary healthcare is hard to achieve. The Taber Integrated Primary Healthcare Project (TIPHP, hereafter referred to as the Taber Health Project [THP]) provides one example of how an integrated primary healthcare project was implemented in one rural Canadian community to achieve better healthcare services delivery. The purpose of this paper is to describe key elements that facilitated the implementation of the THP. First, relevant literature and background information about the project are provided. Second, four change enablers that facilitated the integration of primary healthcare are discussed and illustrated by specific examples. Finally, concluding remarks are offered highlighting the importance of providing local healthcare leaders with accurate and comprehensive information to inform healthcare policy development.

\section{Relevant Literature}

In anticipation of healthcare reform and in response to rising costs, many Canadian healthcare organizations are changing rapidly. The concept of integrated service net- 
works has been introduced to address the traditional separation of hospitals, physicians and payers. Indeed, policy makers are now seeking to understand this concept, sometimes referred to as "organized delivery systems." An organized delivery system is "a network of organizations that provides or arranges to provide a coordinated continuum of services to a defined population and that is held clinically and fiscally responsible for the outcomes and the health status of the population served" (Shortell et al. 1993: 447).

Shortell et al. (1994) identify four critical success factors for the development of effective organized delivery systems, including the ability to create a manageable system in terms of size; conduct relevant population-based health status/needs assessments; embrace capitation-based risk for defined populations; and develop new management and governance models. Correspondingly, seven core capabilities are needed to achieve the requisite levels of integration: development of a new management culture, population-based needs assessment, patient care management systems, technology management systems, continuous improvement processes, information linkages and incentive systems (Shortell et al. 1993).

Based on research conducted in the United States, Shortell et al. (1994) identified three policy-relevant barriers to the formation of integrated systems: (1) the neophyte stage of development of most clinical information systems, (2) a predominant focus on the acute care hospital paradigm and (3) the inability to "manage" managed care. The demand for increased accountability that market and legislative reforms place on healthcare systems represents a major challenge. These systems will be challenged to expand their information capabilities to link patients and providers across all healthcare settings involved in the continuum of care. Towards this end, policy makers must have an informed and realistic understanding of what systems of providers will be able to produce in response to legitimate demands for increased accountability. In addition, most systems across the country are moving towards primary healthcare led, population-based delivery systems and away from the hospital-based, acute care focus of the past. Supporting these efforts, public policy needs to encourage efforts to develop a more broadly based, integrated continuum of primary healthcare delivery.

\section{Background}

The THP is a community-based collaborative project that set out to integrate primary healthcare services in Taber, Alberta, Canada. At the onset of the project, a partnership between the Chinook Health Region (CHR) and the Associate Medical Centre (AMC) physician group was developed. The Medical Services Branch provided funding for physicians, while Alberta Health and Wellness provided funding for the CHR. Following project completion, sustainability was supported by traditional funding sources. 
The partners in this collaboration included the AMC - a partnership of eight physicians and the sole medical clinic in the community - and the Chinook Health Region. CHR's services within this community included a 25-bed acute care hospital (reduced to 17 beds during the initiative), 24-hour emergency room coverage, a 70-bed extended care facility, home care, and public health and rehabilitation services.

Taber refers to a geographic area comprising the town of Taber and the surrounding municipal district located in southeastern Alberta. Taber has approximately 15,000 residents who are younger (mean 29.7 years) than the regional average (35.1 years), with slightly lower education yet higher income than the regional average (CHR 2004). Many employed Taber residents work in the gas and oil industries.

People living in rural areas often experience challenges pertaining to access to and acceptance of healthcare services. Rural residents typically define "health" in terms of having the ability to work (Bushy 1994). Moreover, people in this population describe themselves as self-reliant, possessing a strong work ethic, having strong religious affiliations, preferring to interact with informal support systems and favouring informal negotiated solutions for healthcare concerns. In terms of implementing healthcare, rural communities face several challenges, including shortages of professional staff, limited resources, patient migration and institutional closures (Blumenthal and Kagen 2002). Consequently, community-based healthcare initiatives sensitive to the plight of rural people were integral to the success of this project. Primary healthcare integration in Taber was achieved through the use of four main enablers: (1) community assessment and shared planning; (2) evidence-based, interdisciplinary care; (3) integrated electronic information systems; and (4) investment in change processes and structures.

\section{Community Assessment and Shared Planning}

The first enabler was community assessment and shared planning. Successful integration of primary healthcare depends on gaining an understanding of individual, family and community healthcare needs as well as creating opportunities for healthcare users and providers to come together and use this information to arrive at a shared vision of optimal healthcare delivery. Given rural people's diverse and complex healthcare needs, a "one size fits all" approach (Grol and Grimshaw 2003) was of little value. The importance of understanding community needs cannot be understated; such information was important in terms of knowing where to begin. Independent of this initiative, a community forum was held in response to a highly publicized high school shooting in Taber. During this forum, community needs were identified that were subsequently used by the THP to inform the team's decision-making.

In assessing the needs of this rural community, multiple strategies were used. The local community integration team developed a community capacity map, held com- 
munity focus groups and reviewed service utilization patterns. A community capacity map (McKnight and Kretzmann 1996) was produced using the socio-economic determinants of health (Raphael 2004) as a framework for outlining the resources and supports available in Taber, as well as for providing a profile of the challenges involved in accessing these services. Four community focus groups were held to better understand community members' health-related experiences and their health service priorities. Led by community facilitators, these focus groups used a Focus Conversation Method (Stanfield 2000). Focus group data were subsequently interpreted by an independent consultant. Local healthcare service providers also supplied pertinent service utilization information to the local community integration team. Collectively, this information provided a baseline assessment specific to the healthcare needs of this rural community; this information was used to prioritize and guide the strategies that were utilized during the THP. Not surprisingly, these assessment strategies revealed the following healthcare priorities:

- a need for improved healthcare access and one-stop services;

- a need for professional teamwork to promote seamless healthcare services delivery;

- a need for increased individual healthcare choices;

- a need for health promotion and disease prevention education;

+ a need for greater focus on self-care skills;

+ the development of expanded roles for nurses working in this area.

One of the most important factors that enabled the THP to achieve evidencebased, integrated care was that changes were made with the specific needs of the community in mind. Utilizing a collaborative approach, those involved in the assessment process accurately communicated their findings to community leaders. Together, these individuals (i.e., healthcare providers, community leaders) formulated relevant, clear goals and objectives that guided the implementation process. Collaborative decisionmaking greatly facilitated understanding among all partners and, hence, supported needed change. Each group of healthcare providers needed to have clearly defined role expectations that specified appropriate accountability. Providers identified areas where they could share resources and work more effectively with others. Important to the process was that healthcare outcomes needed to be continually negotiated with all stakeholders (e.g., consumers and professionals) as a way of ensuring high-quality healthcare delivery (Korabek et al. 2004).

In Taber, a fundamental step to achieving improvements was that of including physicians in system-level decision-making. Sensing greater control by government, corporations, administrators and even other healthcare professionals, physicians expressed a loss of autonomy with regard to several aspects of their work. This loss of 
autonomy, along with what physicians described as "treadmill" medicine resulting from "turnstile" volume pressure, led to work-related physician dissatisfaction (Mechanic 2003; Zuger 2004). By implementing a shared planning process, physicians regained their autonomy. Over time, they became actively involved in planning for co-location of services through a Service Agreement with the regional health authority.

Changes within the physician clinic were also fundamental to enhancing communication and team building, both within the clinic and between clinic staff and regional programs. For instance, physicians, nurses and assistants formed a team and coordinated their work efforts in a more efficient manner that included finding ways of effectively working with community and regional health authority resources. When confronted by challenges, team members typically refocused their views and subsequent actions in favour of the best interests of the clients and families they served. This proactive approach, which posed its own set of challenges, enabled healthcare services to be delivered effectively and efficiently by appropriately qualified professionals. Further, it supported medical office assistants in playing a more active role in supporting new clinical integration initiatives. Medical Office Assistants (MOAs) are clinic staff trained to assist physicians in their day to day work, and play a strong role in facilitating the liaison between the operational and clinical functions of the Family Practice teams within the clinic. The THP developed a formal Primary Healthcare Alliance with representation from the CHR and the AMC at both clinical and systems levels. This new, formalized business entity developed local policy in the form of a Service Agreement between the physicians and the regional health authority. The main goal of the coalition was to improve the health status of area residents. Community assessment and shared planning were essential in terms of developing a common purpose aimed at successfully integrating physician healthcare services with those provided by other CHR healthcare professionals.

\section{Evidence-Based Interdisciplinary Care}

The second enabler involved utilizing local evidence as a basis for shifting to interdisciplinary care. The Operational Model (see Figure 1) recognizes that locally, integration must occur simultaneously within an interdisciplinary healthcare environment including medical assessments, clinical management, health education and population health services. The interconnected elements in Figure 1 show "wellness" and "self-care" integrated with "community medical services"; "home support/outreach" and "team-based care" integrated with "emergent/urgent care"; and all these facets of healthcare delivery supporting the optimal functioning of "acute care services." 
figure 1. Primary Health Care Coalition Operational Model
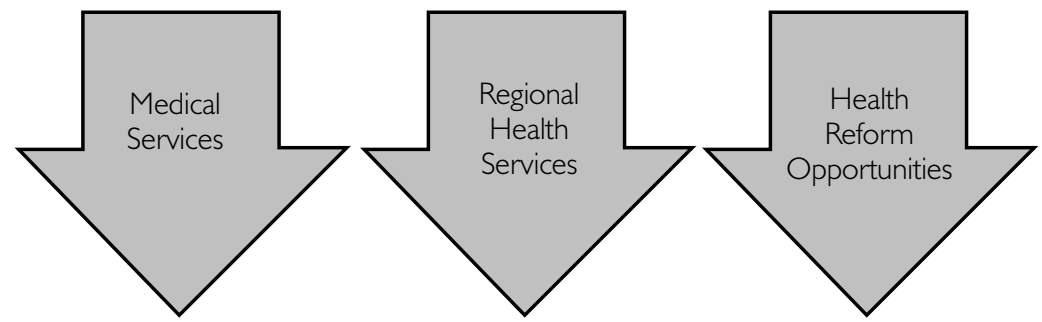

PHC Coalition among autonomous organizations serving a common population through:

I. Community assessment and shared planning

2. Evidence-based, interdisciplinary care

3. Integrated electronic information systems

4. Investments in processes and structures that support change

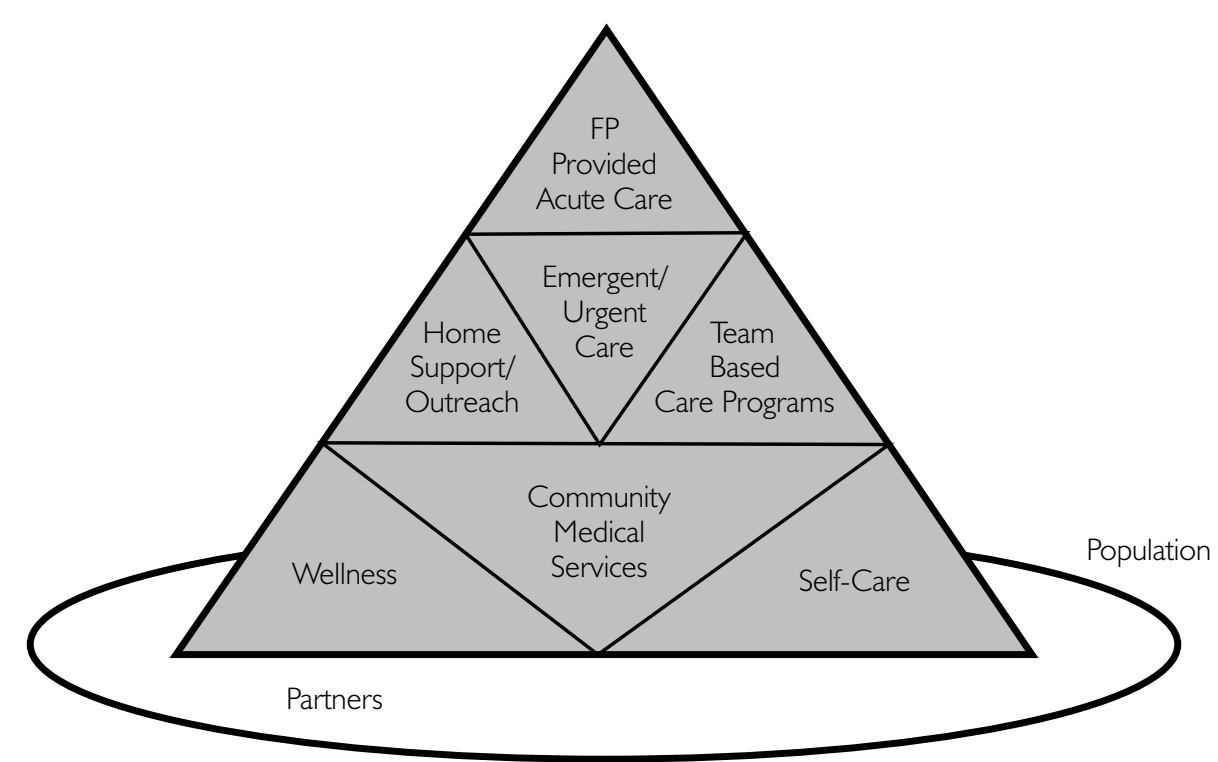

Interdisciplinary team

Once community needs were assessed, those working within the THP used a Collaborative Partnership Model (Korabek et al. 2004) as a basis for forming an interdisciplinary team. This team included physicians, nurses, other front-line healthcare providers and two managers. Using a Program Budget Marginal Analysis (PBMA), supplemented by community assessment information, team members set out to redefine priorities and develop success indicators for health services delivery that would 
lead to efficient and effective, client-centred healthcare outcomes. PBMA is an economic, priority-setting framework used in the healthcare sector to aid decision-makers in establishing priorities for health services required within a region in an evidencebased, transparent fashion. PBMA identifies the means for redirecting resources to those areas of greatest priority so as to maximize health outcomes for the population (Halma et al. 2001). For example, Taber healthcare providers used this framework to improve and integrate chronic disease services within a fixed budget. Healthcare providers first reviewed the current chronic disease management programs in Taber; subsequently, they considered alternatives based on program priorities as well as the costs and benefits of potential changes. Towards this end, a mission statement and a set of goals (Figure 2) were developed and implemented by team members.

\title{
FIGURE 2. Mission statement and goals of the Taber Integration Team
}

\author{
Mission Statement \\ The members of the Taber Integration Team will work to achieve optimal health and wellness for \\ the community we serve through visionary leadership, clinical excellence and strong relationships.

\section{Goals} \\ The Taber Integration Team will work together to achieve: \\ I. Improved communication between care providers and the public \\ 2. Improved awareness of and satisfaction with access and delivery of healthcare services \\ 3. A healthier community through increased health promotion and disease prevention programs.
}

The work done at the interdisciplinary team level was fundamental in shifting healthcare delivery from a facility-based treatment approach to a community-based wellness approach. Allied healthcare professionals such as nurses, respiratory therapists, dieticians and nurse practitioners provided on-site clinical services and also developed broad-based clinical capacity. Specifically, they organized training related to diagnostic equipment use (e.g., spirometers, blood pressure cuffs) and patient education resources (e.g., inhalers, diabetes management supplies), and they also facilitated linkages with external resources (e.g., exercise groups, new mothers' support groups). Three examples illustrating interdisciplinary teamwork within the local healthcare community are provided: well baby services, chronic disease management programs and a well women clinic.

\section{Well Baby services}

The local team used Well Baby (WB) services as a case study to better understand integrated healthcare services delivery. A process of client mapping tracked the typi- 
cal WB appointment pattern with physicians and public health nurses, and provided a flow map showing the timing and content of these routine visits. Client mapping of Taber WB services confirmed a duplication of services. Utilizing an incremental approach to increase system efficiency, the team chose to relocate the public health nurse WB clinics to the medical centre so that patients could save time by booking back-to-back appointments with the public health nurse and the family physician. Duplication was eliminated by coordinating the timing of appointments and services. While maintaining high-quality service delivery, this type of integration saved a typical family four visits during an infant's first year.

Although the initial goal was to increase healthcare services' effectiveness and efficiency, broader benefits also occurred, including increased case finding by the nurses and increased time for preventive patient education. Co-location enabled physicians and public health nurses to provide joint WB visits. This simple change in clinical practice decreased the number of appointments for the clients and simultaneously enhanced communication among healthcare professionals. Through a collaborative effort, practice changes that exceeded the project goals were realized.

\section{Chronic disease management programs}

The lessons learned from the WB case study were applied to other areas of healthcare services integration. In Taber, past healthcare practices utilized numerous, separate clinical working groups in the management of chronic diseases. It soon became evident that a common approach for treating all types of chronic diseases/conditions (e.g., asthma, diabetes and hypertension) would be more efficient and effective. This common approach added value in that it was user friendly for both staff and patients. It also aligned operational processes and reduced the administrative workload for new programs.

The Taber Asthma Program and the Diabetes Education Program are the bestdeveloped team-based programs within this region. Clinical practice guidelines and evidence of best practices from Alberta and Canadian guidelines formed the cornerstone of the Taber Asthma Program. Team members included physicians and certified asthma educators (i.e., CHR respiratory therapists and the AMC nurse practitioner). The program provided clear roles for team members related to asthma assessments, education and treatments that were framed within an Asthma Action Plan. This structure enabled the effective use of healthcare system resources and supported healthcare professionals in implementing best practices. Initially, the regional Diabetes and Lipids Education Program was located in the Taber Health Unit. Subsequently, as a way of enhancing continuity of care, the program was later moved to the medical clinic. 


\section{Well Women clinic}

A review of services utilization revealed that the greatest number of residents accessing services outside the Taber community were women seeking full check-ups, including Pap smears. In response, a nurse practitioner developed the Well Women clinic. Based on clinical practice guidelines, the clinic was supported by the nurse practitioner's scope of practice guidelines and regular consultations with physicians.

Another objective of the WW clinic was to remove some of the burden on rural physicians by appropriately utilizing the expertise of other healthcare professionals. For example, a nurse practitioner provided women with holistic and comprehensive healthcare that, in turn, lessened physicians' workloads and improved outreach services to vulnerable populations. Supporting such practice, Litaker et al. (2003) maintain that physician-nurse practitioner teams can be used to improve clinical effectiveness, to enhance patients' perception of care and to minimize healthcare costs.

The nurse practitioner-led WW service has been particularly useful for women who experience more complex personal and social circumstances, and for those who may require specialized services delivery. For example, young women engaged in highrisk activities, or older women with questions related to menopause, might fall within this category. Overall, this program was well received within the Taber community.

\section{Integrated Electronic Information System}

The third enabler was the utilization of an integrated electronic information system that provided a useful way of achieving high-quality healthcare improvement (Miller and Sim 2004). During this initiative, the CHR was using the Meditech electronic information system. At the beginning of the project, the only electronic information available to physicians was laboratory and hospital admissions data; the AMC was using electronic billing and scheduling as well as paper charting. The regional plan was to roll out the Meditech electronic information systems within all clinical programs in Taber. Similarly, physicians were planning to move to electronic charting.

The outcome was that the Meditech information became available to physicians in both clinic and hospital settings. For example, physician clinic charts were available when patients presented after hours in the Emergency Department. A second example was the move towards "one patient, one chart" as a way of providing effective interdisciplinary care. Even though this goal was not fully realized during this initiative, there were examples of success at specific program levels (e.g., diabetes care). In response to community requests for healthcare access through a single point of entry, a third example included the electronic information system being set up to allow patients to make appointments simultaneously with both the physician and the chronic disease educator. Integrated electronic information systems are now being developed to support interdisciplinary care through linked scheduling and shared access to charting 
systems. Once again, shared planning resulted in the integration of two systems. It is anticipated that this infrastructure will ultimately provide one of the most integrated electronic healthcare systems available.

\section{Investment in Processes and Structures That Support Change}

The fourth enabler involved setting in place processes and structures to support change over the long term. Based on community and research evidence, the management team believed that it was essential to invest time and money in an alternative payment plan for physicians, organizational change and co-location of services.

\section{Alternative Payment Plan}

Financial incentives can be an effective way of changing professional behaviour, especially when the incentives are aligned with professional values and priorities (Roland 2004). An Alternative Payment Plan (APP) was implemented for Taber physicians as a way of clarifying terms of payment, defining service expectations and protecting organizational autonomy. The APP was designed to enable physicians to delegate tasks to their teams, allowing physicians to spend additional time with their more complex patients. Examples of delegated tasks include health screening reminders, proactive surveillance of chronic diseases, and patient education in support of self-care.

New payment mechanisms were based on geographic capitation. This type of payment was based on a provincial population cost formula. In this case, healthcare monies were distributed based on the age and gender profile of Taber residents. This fiscal approach helped physicians pay greater attention to community-level initiatives, as well as individual-level healthcare opportunities and concerns. Since Taber physicians also covered the local Emergency Department within their defined scope of practice, they had a vested interest in broad community healthcare interventions. The APP provided a buffer that supported physicians by rewarding them for the quality of care they delivered and giving them opportunities to innovate in matters of access and care - issues that are extremely important to rural residents.

Internal distribution of the APP funding was based on time spent in the clinic, with incentives for on-call care, indirect care, house calls, palliative care visits, obstetric care and team planning. Limited incentives were developed for accomplishing defined quality indicators. The APP was also used to encourage and support physician lifestyle improvements, such as basic vacation time, continuing medical education and quality time with family, all important aspects of self-care that are sometimes overlooked in a demanding work world. 


\section{Organizational change}

Organizational change strategies were used to address resistance at system and personal levels, as well as to remove barriers at the infrastructure level. The development of the Service Agreement previously discussed set the direction for organizational change and clarified the roles and responsibilities of each partner within the new integrated primary healthcare delivery system. At the system level, the distinct cultures of the

..+ the following challenges were identified: ambiguous roles and responsibilities, lack of commitment and lack of strategic alignment. regional healthcare program offices and the primary healthcare office were recognized, validated and then aligned using the common focus on patient-centred care. Partnership and col-

laboration through management team dialogue helped to anticipate and facilitate organizational change. Personal resistance to change was explored, and team-building strategies (e.g., visioning exercises) were used to build trust among team members. Once individuals from a variety of disciplines were able to build a common vision, attention was then turned towards reducing infrastructure barriers. This aspect was addressed through building renovations and new Information System technology that accelerated the pace at which change could be realized.

\section{Co-location}

Initially, there were three separate health sites in Taber: the hospital, which includes an extended care wing; the AMC physician clinic; and the health unit, where Public Health, Children's Rehabilitative Services and Home Care were located. The team's vision was to develop two re-designed sites. The first was the physician clinic, selected as the site for integrated wellness and chronic disease management services. The second involved developing rehabilitative and transitional programs at the hospital. Towards this end, Home Care and Palliative Care moved into the hospital and the Diabetes and Lipids Education Program moved into the AMC physician clinic. The respiratory therapist moved from the hospital to the AMC physician clinic, which in turn provided support for the Asthma Education Program. Public Health offered most of its clinic services through the AMC physician clinic during this pilot initiative. In several instances, co-location was beneficial in that it led to a significant improvement in communication among healthcare providers. This aspect of the integrated primary healthcare initiative continues to evolve towards a common practice site. 


\section{Public Policy}

Undoubtedly, primary healthcare offers significant benefits to Canadians and to the healthcare system as a whole. The THP provides one example of the successful integration of primary healthcare services within a rural community. Within this initiative, most new interventions were linked to community medical and health services and reflected a shift to interdisciplinary care for wellness and chronic disease services. Positive outcomes have been realized in terms of client satisfaction, health provider satisfaction, perceived improvements in quality of care and improved utilization rates. The Taber initiative has contributed to the body of knowledge that has guided primary healthcare renewal initiatives included within a provincial Master Agreement among the AMA, Alberta Health and Wellness and CHR (newly named Chinook Health). In the future, this eight-year agreement includes a new funding scheme for "Primary Care Networks" in Alberta, which facilitates the development of partnerships between physician groups and regional health authorities, and allows for the implementation of new primary care renewal strategies within these Networks. Importantly, the THP has contributed to regional healthcare policy through the development of our own Chinook Primary Care Network, which includes strategies to improve access and enhance team-based care.

\section{Catalysts and Challenges}

Although the project, as presented here, seems to have been implemented with ease, this was not the case. It took a great deal of work to ensure that all stakeholders remained committed to it. Without the diligent efforts of some of the physicians, managers and other healthcare staff in promoting this project, it would not have been successful. Key individuals were instrumental in providing support to this initiative as they stepped outside traditionally established boundaries. These people were committed to making a change, had a clear vision of the goals of the project and supported others in creating needed change.

Within this initiative, the following challenges were identified: ambiguous roles and responsibilities, lack of commitment and lack of strategic alignment. Healthcare professionals were sometimes uncertain about their roles and responsibilities. The process of breaking down the silos among healthcare professionals frequently induced fear among those attempting to implement change. In the early stages of the initiative, there was a common perception that the proposed change would result in decreased healthcare provider autonomy and power. Similarly, a lack of major stakeholder buy-in and commitment at the community, provincial and national levels was another challenge. Finally, the lack of strategic alignment by key stakeholders resulting from their inability to converge on a common purpose was identified as a challenge. 


\section{Conclusion}

The THP demonstrated the effectiveness of one model of primary healthcare that resulted in the successful integration of healthcare services for improved healthcare outcomes. This primary healthcare initiative is sustainable, and in fact continuing to develop through provincial funding supporting Primary Care Networks in Alberta. Chronic disease management will be sustained, and ongoing negotiations are expected to achieve full co-location between the medical and regional healthcare teams.

The THP brings to light the ways in which a team of healthcare professionals endeavoured to integrate primary healthcare within one healthcare region. The catalysts and challenges they encountered are congruent with those cited in the literature (e.g., Halma et al. 2001; Shortell et al. 1993, 1994). Key elements of the model described in this paper, most notably the four enablers, helped healthcare professionals residing in one rural community to turn vision into reality.

Correspondence may be directed to: Robert Wedel, MD, Medical Director, Palliative Care, Chinook Health Region, 5016 - 48 Ave., Taber, AB T1G 1R8; tel.: 403-223-4652; e-mail: rwedel@telusplanet.net.

\section{REFERENCES}

Alberta Health and Wellness. 2002. Alberta: Health First. Alberta Government Response to the Premier's Advisory Council on Health. Building a Better Public Health Care System Report. Retrieved June 12, 2007. <http://www.health.gov.ab.ca/resources/health_first.htm>.

Beddome, G., H. Clarke and N. Whyte. 1993. "Vision for the Future of Public Health Nursing: A Case for Primary Health Care." Public Health Nursing 10: 13-18.

Blumenthal, S. and J. Kagen. 2002."The Effects of Socioeconomic Status on Health in Rural and Urban America." Journal of the American Medical Association 287(1): 109.

Bushy, A. 1994. "When Your Client Lives in a Rural Area, Part 1: Rural Health Care Delivery Issues." Issues in Mental Health Nursing 15(3): 253-66.

Chinook Health Region (CHR). 2004 (August). Community Perspectives 2: 1. Retrieved June 12, 2007. <http://www.chr.ab.ca/about_chr/2001CNPass.pdf >.

Grol, R. and J. Grimshaw. 2003. "From Best Evidence to Best Practice: Effective Implementation of Change in Patients' Care." Lancet 362(9391): 1225-30.

Halma, L., C. Mitton, C. Donaldson and B. West. 2001. “A Case Study on Priority Setting in Rural Southern Alberta: Keeping the House from Blowing In." Canadian Journal of Rural Medicine 9(1): 26-36.

Korabek, B., P. Rosenau, C. Slauenwhite and L. Ross. 2004. “Home Care/Physician Partnerships in the Community: A Canadian Model in Development." Home Health Care Management E Practice 16(4): 261-68. 
Litaker, D., L. Mion, L. Planavsky, C. Kippes, N. Mehta and J. Frolkis. 2003. “Physician-Nurse Practitioner Teams in Chronic Disease Management: The Impact on Costs, Clinical Effectiveness, and Patients' Perception of Care." Journal of Interprofessional Care 17(3): 223-37.

Mazankowski, D., M. Abdurahman, L. Bryan, L. Cranston, B.L. Crowley, L. Douglass, J. Evans, J.D. Graham, M.D. Low, K. Nickersen, A. O’Brien and E. Smith. 2001 (December). A Framework for Reform: Report of the Premier's Advisory Council of Health. Retrieved June 12, 2007. <http:// web.uvic.ca/ schaafsm/Mazankowski_report.pdf>.

McKnight, J.L. and J.P. Kretzmann. 1996. Mapping Community Capacity. Evanston, IL: Institute for Policy Research Northwestern University.

Mechanic, D. 2003. "Physician Discontent: Challenges and Opportunities." Journal of the American Medical Association 290(7): 941-46.

Miller, R. and I. Sim. 2004. "Physicians' Use of Electronic Medical Records: Barriers and Solutions." Health Affairs 23(2): 116.

Raphael, D. 2004. Social Determinants of Health: Canadian Perspectives. Toronto: Canadian Scholar's Press.

Roland, M. 2004. “Linking Physicians' Pay to the Quality of Care - A Major Experiment in the United Kingdom." New England Journal of Medicine 351(14): 1448-54.

Romanow, R.J. 2002. Building on Values: The Future of Health Care in Canada. Final Report of the Commission on the Future of Health Care in Canada. Retrieved June 12, 2007. <http://www.hcsc.gc.ca/english/pdf/romanow/pdfs/HCC_Final_Report.pdf $>$.

Shortell, S.M., R.R. Gillies and D. Anderson. 1994."The New World of Managed Care: Creating Organized Delivery Systems." Health Affairs Chevy Chase 13(5): 46-65.

Shortell, S.M., R.R. Gillies, D.A. Anderson, J.B. Mitchell and K.L. Morgan. 1993. “Creating Organized Delivery Systems: The Barriers and Facilitators." Hospital and Health Services Administration 38(4): 447-66.

Stanfield, R.B., ed. 2000. "Leading a Focused Conversation: A Summary." The Art of Focused Conversation: 100 Ways to Access Group Wisdom in the Workplace (pp. 203-6). Toronto: Canadian Institute for Cultural Affairs.

Starfield, B. and L. Shi. 2002. "Policy Relevant Determinants of Health: An International Perspective." Health Policy 60: 201-18.

Zuger, A. 2004. "Dissatisfaction with Medical Practice." New England Journal of Medicine 350(1): 69-73. 